\title{
Study of adverse events of A/H1N1 vaccine among health care staff in selected provinces of Afghanistan, 2010
}

\author{
J.A. Mofleh, ${ }^{1}$ Z. Akbarian, ${ }^{2}$ N. Muserat, ${ }^{3}$ H. Yosofi, ${ }^{4}$ A. Alkozai ${ }^{5}$ and B. Noormal ${ }^{6}$
}

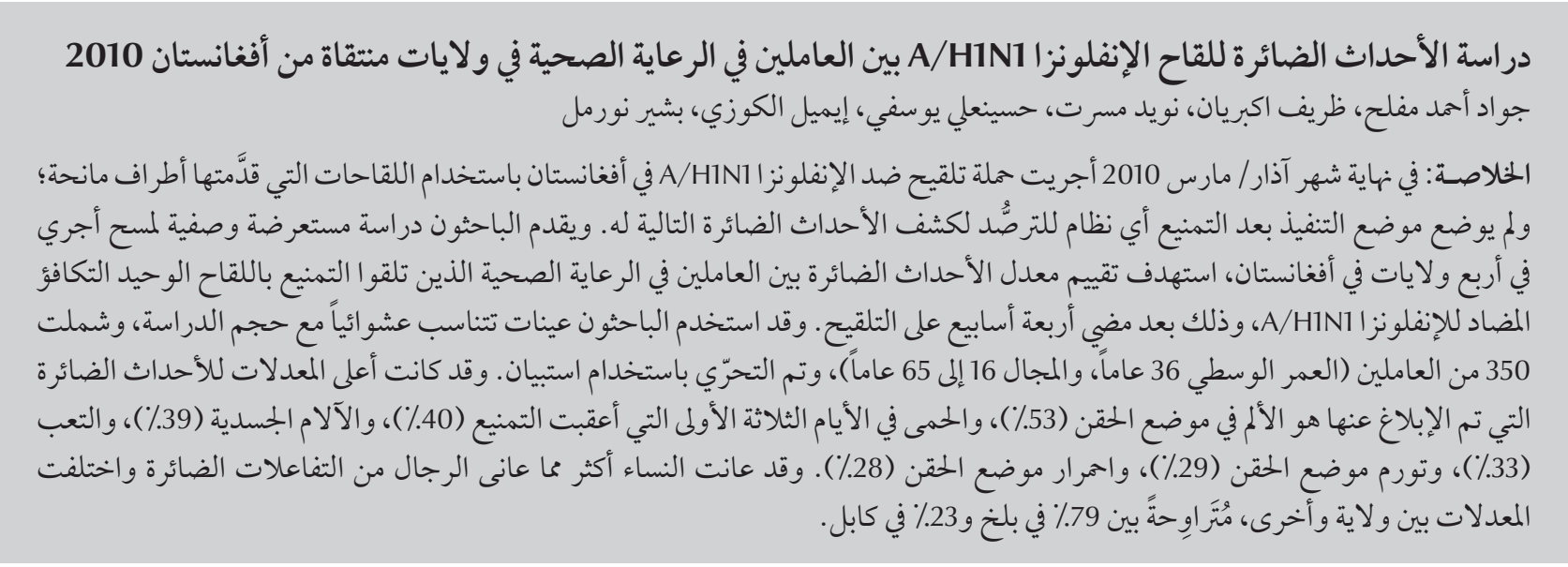

ABSTRACT At the end of March 2010 an A/H1N1 vaccination campaign was conducted in Afghanistan using donated vaccines. However, no surveillance system for detection of adverse events following immunization was in place. We report a cross-sectional, descriptive survey in 4 provinces of Afghanistan to assess the rate of adverse events among health care staff immunized with A/H1N1 monovalent vaccine 4 weeks after vaccination. Using random sampling proportionate to size, 350 staff (mean age 36 years, range 16-65 years) were surveyed using a questionnaire. The highest self-reported rates of adverse events were pain at the injection site (53\%), fever in the first 3 days after immunization (40\%), body pain (39\%), tiredness (33\%), swelling at the injection site (29\%) and redness at the injection site (28\%). More females than males suffered adverse reactions and the rates varied across different provinces, ranging from $79 \%$ in Balkh to $23 \%$ in Kabul.

Étude des manifestations indésirables suite à la vaccination contre la grippe $\mathrm{A}$ (H1N1) chez les agents de santé dans des provinces afghanes sélectionnées sur l'année 2010

RÉSUMÉ Fin mars 2010, une campagne de vaccination contre la grippe A (H1N1) a été menée en Afghanistan avec des vaccins faisant l'objet de dons. Toutefois, aucun système de surveillance pour détecter les manifestations postvaccinales indésirables n'était en place. Nous transmettons les résultats d'une enquête descriptive transversale, menée dans quatre provinces de l'Afghanistan pour évaluer le taux de manifestations postvaccinales indésirables chez les agents de santé vaccinés avec le vaccin monovalent contre la grippe A (H1N1) quatre semaines après l'injection. Sélectionnés par échantillonnage aléatoire proportionnel, 350 agents de santé (âge moyen: 36 ans, fourchettes : 16-65 ans) ont participé à l'enquête en répondant à un questionnaire. Les manifestations postvaccinales indésirables les plus fréquemment déclarées étaient une douleur au niveau du site d'injection (53\%), de la fièvre dans les trois premiers jours suivant la vaccination (40\%), des courbatures (39\%), de la fatigue (33\%), un gonflement (29\%) ou une rougeur (28\%) au niveau du site d'injection. Les femmes étaient plus nombreuses que les hommes à être affectées par des réactions indésirables et les taux de réaction variaient entre les provinces, allant de $79 \%$ dans la province de Balkh à $23 \%$ dans la province de Kaboul.

${ }^{7}$ Eastern Mediterranean Public Health Network; ${ }^{2}$ Disease Early Warning System (DEWS) Office, Western Region; ${ }^{3}$ DEWS Office Central Region; ${ }^{4}$ DEWS Office Northern Region; ${ }^{5}$ DEWS Office Eastern Region; ${ }^{6}$ Afghan Public Health Institute, Ministry of Public Health, Kabul, Afghanistan (Correspondence to J.Mofleh:jmofleh@yahoo.com).

Received: 11/07/11; accepted: 02/11/11 


\section{Introduction}

Emergence of the $\mathrm{A} / \mathrm{H} 1 \mathrm{N1} / 2009$ virus in early 2009 was the trigger for the first pandemic influenza this century [1]. The virus spread to several countries within weeks, which reduced the possibility of rapid containment to zero, and the World Health Organization (WHO) declared pandemic influenza on 11 June 2009 [2]. By the time the virus was detected it was widespread in Mexico, parts of the United States and Canada, hence the rapid containment of the disease was practically impossible, and other recommendations of the International Health Regulations, e.g. pharmaceutical and not pharmaceutical interventions, were implemented. On the principle of access to health and treatment, after declaration of phase 5 , WHO started deploying 3 million doses of the antiviral drug osletamivir to Mexico and to 71 pre-identified low-income countries, of which 50000 doses of the medicine reached Afghanistan by October 2009. Influenza A/H1N1 monovalent vaccine was licensed in September 2009 and was on the market by the end October $2009[3,4]$. Use of this vaccine was considered to be safe by producers, the Centers for Disease Control and WHO [5-9]. A total of 78 million doses of pandemic influenza vaccine were deployed to 77 countries in 2009 and 2010.

In February 2010 Afghanistan received 0.5 million doses of GlaxoSmithKline pandemic influenza vaccine to protect the health workforce, pregnant women, young children and people with chronic illnesses. The Ministry of Public Health in Afghanistan decided to vaccinate health care staff first and planned to receive more vaccine for other high-risk groups later. Influenza vaccination was not part of the routine regime of vaccination in the country and therefore no surveillance system for detection of adverse events following immunization (AEFI) with influenza vaccine was in place. Also as the vaccines reached Afghanistan at the peak of pandemic influenza, the vaccination campaign was conducted immediately to ensure the integrity of the health system in Afghanistan and prevent a collapse in the system. This paper reports a survey to assess the rate of self-reported AEFI among a sample of health care staffimmunized with $\mathrm{A} / \mathrm{H} 1 \mathrm{~N} 1$ monovalent vaccine in 4 provinces of Afghanistan in 2010 .

\section{Methods}

\section{Study design}

This was a descriptive, cross-sectional study with a simple random sampling proportionate to size method. Afghanistan received the donation of vaccines from WHO in February 2010 and the vaccination campaign was conducted at the end of March 2010. This study was conducted at the end of April 2010, just over 4 weeks after administration of the vaccines.

\section{Study setting and sample}

The study was conducted in the 4 major provinces of Kabul, Nangarhar, Balkh and Herat. Health facilities in the selected provinces were the sampling frame and the subjects were health care workers who received H1N1 vaccination. Health care facilities were randomly selected from the list of health facilities that received the vaccine. Study candidates were also selected randomly from the list of the health care workers receiving vaccination in the respective health facilities. A total of 27100 people received $\mathrm{A} / \mathrm{H} 1 \mathrm{~N} 1$ monovalent vaccine in these 4 provinces of Afghanistan. OpenEpi was used to draw a sample of 417 from the pool of subjects.

\section{Data collection}

A questionnaire was developed, field tested and applied to all study candidates by a team of 11 qualified trained surveyors who conducted the interviews and filled the questionnaires. Oral consent from participants was obtained prior to interview. Reports of local AEFI were all subjective and based on the respondents' own reports. Reports of systemic AEFI were verified where possible by medical doctors and were registered.

\section{Analysis}

The data were entered to Epi Info database and analysed using Epi Info and Microsoft. Excel statistical packages. The rates of adverse reactions or adverse events were compared with the manufacturer's reported rate of adverse events following immunization with the influenza monovalent vaccine [10]. The manufacturer categorized the AEFI as: common $(>1 / 100$ but $<1 / 10$ people $)$, uncommon $(>1 / 1000$ but $<1 / 100)$, rare $(1 / 10000$ but $<1 / 1000)$ and very rare $(<1 / 10000)$.

\section{Results}

\section{Background characteristics}

After excluding forms with inaccurate or missing data 360 of the selected candidates were included in the study: 91 (25\%) females and 279 (75\%) males; $86 \%$ were married. The mean age was 36 years, range $16-65$ years. There were 137 in Kabul (103 males/34 females), 87 in Nangarhar (64 males/ 14 females), 66 in Balkh (48 males/18 females) and 80 in Herat ( 55 males $/ 25$ females). The distribution by educational level showed 44 (12\%) staff with no education (i.e. ancillary staff), 23 (6\%) primacy education, 13 (4\%) secondary education, 39 (11\%) high school graduates, 142 (39\%) paramedical (12-15 years of education) and 100 (28\%) university graduates.

\section{Adverse events reported}

Table 1 summarizes the rate of each adverse event. Pain at the site of injection 


\begin{tabular}{|c|c|c|c|c|c|c|}
\hline \multirow[t]{2}{*}{ Adverse event } & \multicolumn{2}{|c|}{$\begin{array}{c}\text { Females } \\
(n=91)\end{array}$} & \multicolumn{2}{|c|}{$\begin{array}{c}\text { Males } \\
(n=270)\end{array}$} & \multicolumn{2}{|c|}{$\begin{array}{l}\text { Both sexes } \\
(n=361)\end{array}$} \\
\hline & No. & $\%$ & No. & $\%$ & No. & $\%$ \\
\hline Pain at injection site & 56 & 62.2 & 136 & 50.4 & 192 & 53.2 \\
\hline Body pain & 44 & 48.9 & 96 & 35.6 & 140 & 38.9 \\
\hline Fever & 44 & 48.9 & 100 & 37.0 & 144 & 40.0 \\
\hline Tiredness & 33 & 36.7 & 87 & 32.2 & 120 & 33.3 \\
\hline Swelling at injection site & 33 & 36.7 & 71 & 26.3 & 104 & 28.9 \\
\hline Hardness at injection site & 29 & 32.2 & 57 & 21.7 & 86 & 23.9 \\
\hline Redness at injection site & 27 & 30.0 & 72 & 26.7 & 99 & 27.5 \\
\hline Muscle pain & 27 & 30.0 & 67 & 24.8 & 94 & 26.1 \\
\hline Chills & 24 & 26.7 & 24 & 8.9 & 48 & 13.3 \\
\hline Headache & 23 & 25.4 & 52 & 19.3 & 75 & 20.8 \\
\hline Muscle weakness & 14 & 15.6 & 42 & 15.6 & 56 & 15.6 \\
\hline Shivering & 12 & 13.3 & 15 & 5.6 & 27 & 7.5 \\
\hline Sweating & 10 & 11.0 & 20 & 7.4 & 30 & 8.3 \\
\hline Fainting & 9 & 10.0 & 24 & 8.9 & 33 & 9.2 \\
\hline Coryza & 9 & 10.0 & 17 & 6.3 & 26 & 7.2 \\
\hline Hypotension & 9 & 10.0 & 15 & 6.5 & 24 & 6.7 \\
\hline Numbness & 6 & 6.7 & 12 & 4.4 & 18 & 5.0 \\
\hline Tingling & 6 & 6.7 & 9 & 3.3 & 15 & 4.2 \\
\hline Insomnia & 5 & 5.6 & 17 & 6.3 & 22 & 6.1 \\
\hline Tinnitus & 5 & 5.6 & 9 & 3.3 & 14 & 3.9 \\
\hline Neuralgia & 4 & 4.4 & 6 & 2.2 & 10 & 2.8 \\
\hline Generalized rash & 4 & 4.4 & 4 & 1.5 & 8 & 2.2 \\
\hline Blurred vision & 2 & 2.2 & 8 & 3.0 & 10 & 2.8 \\
\hline Hypertension & 2 & 2.2 & 1 & 0.4 & 3 & 0.8 \\
\hline Bruising & 2 & 2.2 & 1 & 0.4 & 3 & 0.8 \\
\hline Convulsion & 1 & 0.0 & 2 & 0.7 & 3 & 0.8 \\
\hline Bleeding & 1 & 0.0 & 1 & 0.4 & 2 & 0.6 \\
\hline Vasculitis & 0 & 0.0 & 3 & 1.1 & 3 & 0.8 \\
\hline
\end{tabular}

was the most common AEFI, reported by $53 \%$ of study participants. Other local reactions-swelling, redness and hardness at the injection site-were reported by $29 \%, 28 \%$ and $24 \%$ of respondents respectively. Some of the study participants (13\%) experienced all the classic signs of local inflammation (heat, redness, swelling and pain).

The second most common AEFI was a systemic one, fever in the first 3 days after immunization, reported by $40 \%$ of respondents. Some of the respondents (9\%) had all the signs of local inflammation plus fever and
5 (1\%) reported all the injection site effects together with fever, body pain and shivering. Overall, $10 \%$ of the study participants reported influenza-like illness in the first 7 days after the influenza vaccination.

Body pain was the third most common complain, experienced by $39 \%$ of all those who received vaccine: $49 \%$ among females versus 36\% among males. Other common complaints reported by respondents were: tiredness (33\%), muscle pain (26\%), headache (21\%), muscle weakness (16\%), chills (13\%) and fainting (9\%). Blurred vision, neuritis, bleeding, vasculitis and convulsions were rarely reported $(0.3 \%, 0.3 \%, 0.6 \%, 0.8 \%$ and $0.8 \%$ respectively).

No infections at the site of injection, purulent discharge from the site of injection, anaphylactic shock or deaths were recorded after influenza immunization.

\section{Adverse events reported by demographic characteristics}

Feelings of pain at the injection site were experienced by more females (62\%) than male respondents (50\%). Fever was also more common among females 
(54\%) than males (37\%). The rate of fever was 63\% in Nangarhar, 56\% in Herat, $49 \%$ in Balkh and $16 \%$ in Kabul. Pain at the injection site differed across residents of different provinces, ranging from $79 \%$ in Balkh to $23 \%$ in Kabul. The highest rate of pain among females was reported in Nangarhar province (93\%), followed by Herat (84\%), Balkh (72\%) and Kabul (26\%). Experience of AEFI also varied by educational level. Pain was reported more in those with only had primary education (83\%), followed by university graduates (58\%), high-school graduates $(55 \%)$, no education (ancillary staff) (54\%), paramedics (46\%) and secondary education (39\%).

\section{Discussion}

The study showed that the highest rate of AEFI was a local one - pain at the injection site-in 53\% of participants. A systemic AEFI—fever — was reported by $40 \%$. All the classic signs of local inflammation (heat, redness, swelling and pain) were reported by $13 \%$ of subjects. The findings of this study agree with a study conducted in Australia, in which the highest rate of adverse events were systemic (53.8\%) and injection site events (56.3\%) [11]. However, comparing the results of this study with similar studies conducted in the United States of America and Canada prior to the licensing of the $\mathrm{A} / \mathrm{H} 1 \mathrm{~N} 1$ vaccine $[5]$ (Table 2 ) show much higher rates of pain, redness and swelling at the injection site in our study and for all adverse events in this study except for headache. The findings were also not replicated in another study conducted in Canada in 2010 [12] and a multi-centre double-blind randomized trail conducted in China in 2009 in which the authors reported a local reaction of $5.3 \%$ and pain of $4.6 \%$ among a sample size of over 11400 individuals who received the

$\begin{aligned} & \text { Table 2 Comparison of the rates of adverse events in the current study in } \\
& \text { Afghanistan with data from the United States of America (USA) and Canada prior } \\
& \text { to the licensing of the A/H1N1 vaccine [5] }\end{aligned}$
\begin{tabular}{lrcc} 
Adverse event & Rate of adverse event (\%) \\
& Canada & $\begin{array}{c}\text { Afghanistan } \\
\text { (current study) }\end{array}$ \\
Pain & 24 & 21 & 53 \\
Fever & 11 & 1 & 40 \\
Fatigue & 17 & 10 & 33 \\
Redness & 11 & 14 & 28 \\
Swelling & 10 & 6 & 29 \\
Myalgia & 13 & 11 & 26 \\
Headache & 28 & 10 & 21 \\
Chills & 5 & 3 & 13 \\
\hline
\end{tabular}

first dose of the influenza vaccine [13]. However, a study in Canada reported that the incidence of AEFI was higher in those who received higher doses of the AH1N1 vaccine compared with those who received lower doses of the vaccine and this may be one of the reasons for a higher number of adverse effects in Afghanistan.

There are many factors that can contribute to higher rates of adverse effects following immunization: a higher dose than recommended may be administered, (e.g. $>15 \mu \mathrm{g}$ ); poor training of injectors may increase the risk of AEFI (e.g. shallow or deep injections may cause pain, redness and swelling of the injection site); and knowledge of participants about adverse events may lead to bias in answering. Among many difficulties that Afghanistan faced in this the first ever influenza vaccination campaign in the country were limited trained vaccinators, limited capacity for the logistic of vaccines which were not included in the routine immunization schedule, willingness of the vaccine recipients and attitudes of people toward the vaccine and vaccine safety.

This study had some limitations which should be noted. A cross-sectional study was conducted, while a prospective, cohort study would have been better. The results were a snapshot which was taken 4 weeks after vaccination. No objective measures were included in the study; all responses were based on the participants' self-reports and we could not clinically verify their the administration of the vaccine. As most of the reactions were mild and the study population was health care workers they were either self-treated or treated by colleagues without proper registration of the adverse event. No AEFI surveillance system for influenza vaccination was available in Afghanistan to compare our data with. The study was conducted only 4 weeks after implementation of the influenza vaccination campaign and therefore no delayed reactions/adverse effects were recorded.

Nevertheless, this was the first time that a major influenza vaccination campaign was conducted at the country level and it provides useful baseline data for future research. Implementation of an $\mathrm{H} 1 \mathrm{~N} 1$ vaccination campaign needs in-depth planning, logistics and training to reduce associated adverse effects and ensure injection safety. A proper AEFI surveillance system should be implemented to capture all events associated with the immunization. responses because it was 4 weeks after 


\section{References}

1. Influenza-like illness in the United States and Mexico. Briefing note, 24 April 2009. Geneva, World Health Organization, 2009 (http://www.who.int/csr/don/2009_04_24/en/index.html, accessed 31 July 2012).

2. DG statement following the meeting of the emergency committee. Briefing note, 11 June 2009. Geneva, World Health Organization, 2009 (http://www.who.int/csr/disease/swineflu/4th_ meeting_ihr/en, accessed 31 July 2012).

3. Use of influenza A (H1N1) 2009 monovalent vaccine. Recommendations of the Advisory Committee on Immunization Practices (ACIP), 2009. Morbidity and Mortality Weekly Report, 2009, 58(early release):1-8.

4. Pandemic influenza vaccines: current status. Pandemic (H1N1) 2009. Briefing note 11, 24 September 2009. Geneva, World Health Organization, 2009 (http://www.who.int/csr/disease/ swineflu/notes/pandemic_influenza_vaccines_20090924/ en/index.html, accessed 31 July 2012).

5. Safety of pandemic influenza A(H1N1) 2009 vaccines. Extract from report of GACVS meeting of 8-9 December 2010, published in the WHO Weekly Epidemiological Record on 28 January 2011. Geneva, World Health Organization, 2011 (http:// www.who.int/vaccine_safety/topics/influenza/pandemic/ h1n1_safety_assessing/Dec_2010/en/index.html, accessed 31 July 2012).

6. Safety of pandemic A (H1N1) influenza vaccines. Extract from report of GACVS meeting of 3-4 December 2009, published in the WHO Weekly Epidemiological Record on 29 January 2010. Geneva, World Health Organization, 2010 (http:// www.who.int/vaccine_safety/topics/influenza/pandemic/ h1n1_safety_assessing/Dec_2009/en/index.html, accessed 31 July 2012).
7. Safety of pandemic vaccines. Pandemic (H1N1) 2009. Briefing note 6, 6 August 2009. Geneva, World Health Organization, 2009 (http://www.who.int/csr/disease/swineflu/notes/ h1n1_safety_vaccines_20090805/en/index.html, accessed 31 July 2012).

8. Pandemic influenza vaccines: current status, Pandemic (H1N1) 2009. Briefing note 11, 24 September 2009 Geneva, World Health Organization, 2009 (http://www.who.int/csr/disease/ swineflu/notes/pandemic_influenza_vaccines_20090924/ en/index.html, accessed 31 July 2012).

9. Safety of pandemic (H1N1) 2009 vaccines. Briefing note, 30 October 2009. Geneva, World Health Organization, 2009 (http:// www.who.int/csr/disease/swineflu/frequently_asked_questions/vaccine_preparedness/safety_approval/en/index. html, accessed 31 July 2012).

10. Highlights of prescribing information. Quebec City, GlaxoSmithKline, 2010 (http://www.fda.gov/downloads/BiologicsBloodVaccines/Vaccines/ApprovedProducts/UCM190377. pdf, accessed 8 August 2012).

11. Greenberg ME et al. Response to a monovalent 2009 influenza A (H1N1) vaccine. New England Journal of Medicine, 2009, 361:2405-2413.

12. Summary of Manitobans vaccinated for pandemic H1N1 influenza. Surveillance report, 7 February 2010. Winnipeg, Manitoba, Province of Manitoba Health Department, 2010 (http://www. gov.mb.ca/health/publichealth/surveillance/h1n1/stats4. html\#2, accessed 31 July 2012).

13. Liang XF JZ et al. Safety and immunogenicity of 2009 pandemic influenza A H1N1 vaccines in China: a multicentre, double-blind, randomised, placebo-controlled trial. Lancet, 2010, 375:56-66. 